

\title{
CONTROLE E QUALIDADE NO RECEBIMENTO DO CONCRETO DOSADO EM CENTRAL
}

\author{
ARANTES, Gustavo M. (1); VAZ, Fernando H. B. (2); BRANDSTETTER, Maria \\ Carolina G. O. (3)
}

(1) (2) (3)Programa de Pós-Graduação em Geotecnia, Estruturas e Construção, Escola de Engenharia Civil, Universidade Federal de Goiás, e-mail: maria.carolina@uol.com.br

\begin{abstract}
RESUMO
O controle em obra quanto ao recebimento do concreto dosado em central tem sua importância evidenciada devido à necessidade da manutenção da qualidade das estruturas. Esta etapa de grande importância que recebe atenção normativa pode estar sendo negligenciada em obras por falhas relacionadas à gestão. Tal negligência pode trazer consequências negativas desde gastos que poderiam ser minimizados até manifestações patológicas nas estruturas que afetam a estética, durabilidade e desempenho da edificação. O objetivo do trabalho consiste no levantamento de falhas relativas ao controle de qualidade na etapa de recebimento do concreto usinado nos canteiros de obra. De cunho exploratório, foram feitos quatro estudos de caso na cidade de Goiânia em empresas com sistemas certificados de gestão da qualidade. O método abrangeu a aplicação de checklists elaborados a partir da análise aprofundada de itens preconizados pela NBR 12655. A investigação abrangeu o emprego de ações para o acompanhamento dos critérios indicados em projetos estruturais, bem como do pedido feito às concreteiras, da chegada do concreto na obra, sua verificação in loco, além da análise de laudos laboratoriais. Entre os principais resultados, as não conformidades nas obras visitadas foram categorizadas em relação aos projetos, ensaios, ações de controle, responsabilidades dos projetistas, executores de obras e concreteiras. Foram correlacionadas possíveis consequências como manifestações patológicas em revestimentos e vedações, além de prejuízos em cronogramas. A pesquisa também propõe uma lista de indicadores de qualidade do concreto para a etapa do recebimento em obra. O trabalho contribui para fomentar a discussão da necessidade de um maior controle por parte dos construtores em relação à eficácia de suas medidas de controle, seus métodos e recursos empregados, em especial diante do aumento contínuo de oferta de empreendimentos, da exigência do cumprimento de prazos de entrega e dos aspectos levantados pela nova norma de desempenho.
\end{abstract}

Palavras-chave: Qualidade, Controle, Recebimento, Concreto.

\begin{abstract}
The control in concrete acceptance in work sites is important to maintain building structures quality. This important stage, that receives attention norms, can be neglected in works by management failures. This negligence can bring negative consequences by pathological manifestations that affect building aesthetics, durability and performance. The aim of research was to study failures related to quality control in concrete acceptance. Exploratory, were conducted four case studies in Goiania. The companies had certified quality management systems. The method covered application of checklists based on items according to standard NBR 12655. The research included criteria specified in structural projects, the concrete request, the concrete arrival in work site, its verification in situ and laboratory reports analysis. Among the main results, the non-conformities in works sites were categorized in relation to projects, tests, control actions, responsibilities of designers, engineers and concrete producers. Were correlated possible consequences such as pathological manifestations in wall coverings and masonry. The study also proposes a list of quality indicators to the acceptance stage of concrete. The work contributes to discussion on need for a greater control on measures, methods and resources, considering the continued increase in buildings supply, the shortest time of delivery and the fulfillment of requisites established in Brazilian NBR 15575 standard.
\end{abstract}


Keywords: Quality, Control, Acceptance, Concrete.

\section{INTRODUÇÃO}

Com o aumento da oferta de empreendimentos nos centros urbanos, consequente diminuição do tempo de ciclo produtivo e o advento de novas exigências normativas tais como a norma de desempenho NBR 15575 (ABNT, 2013), as empresas passaram a repensar suas medidas de controle de qualidade. Um dos momentos cruciais para o desempenho das edificações é o controle sobre as estruturas de concreto e o comprometimento de sua conformidade.

Ainda que de indiscutível importância, o concreto não é único, possuindo grande variabilidade entre seus vários parâmetros, como resistência característica, formas de aplicação, trabalhabilidade, entre outros. Conhecer cada característica do concreto usinado comumente utilizado na região é de suma importância para entender quais as razões que fazem com que a caracterização de qualidade do produto se altere (OBATA; SOUZA, 2001).

Na pesquisa de Cupertino (2013) que analisou a origem das manifestações patológicas a partir de banco de dados de assistência técnica de edificações residenciais, cerca de $44 \%$ das manifestações patológicas são provenientes da etapa de execução das obras e $22 \%$ são atribuídas aos materiais.

Portanto a falta de planejamento na especificação e recebimento do concreto, juntamente com o fato de ser o responsável por suportar diretamente os esforços nas edificações faz com que o concreto seja dentre os materiais um dos que mais se deve ter atenção no momento de sua chegada à obra.

Entre as hipóteses de erros comuns no recebimento deste material está o fato de que pessoas consideradas menos preparadas ou inaptas a receber o concreto acabam por aceitar um produto que não cumpre os requisitos mínimos para utilização ou ainda tais requisitos sequer sejam controlados, sem que seja percebida esta falha no momento da entrega. As consequências variam desde gastos que poderiam ser minimizados até manifestações patológicas nas estruturas que afetam a estética, durabilidade, desempenho e a resistência da edificação.

O objetivo deste trabalho é analisar falhas relativas ao controle de qualidade na etapa de recebimento do concreto usinado nos canteiros de obra, por meio de um estudo de múltiplos casos. Por meio de verificações preconizadas na NBR 12655 (ABNT, 2006), buscou-se qualificá-las em obras na região metropolitana de Goiânia, Goiás. A pesquisa pressupõe o emprego de ações para o acompanhamento dos critérios indicados em projetos estruturais, bem como do pedido feito às empresas concreteiras, como este concreto chegou e foi verificado in loco, além da análise de laudos laboratoriais.

A contribuição do trabalho está na investigação específica de uma etapa de suma importância na execução dos empreendimentos pouco explorada na literatura, o que permitiu gerar análises e discussões a respeito das responsabilidades do projetista, concreteira, executor da obra e ações de controle.

\section{SÍNTESE DA REVISÃO}

A NBR 12655 (ABNT, 2006) que trata sobre procedimentos de preparo, controle e recebimento de estruturas de concreto, dispõe inicialmente que se tratando de concreto preparado por empresa de serviço de concretagem, a responsabilidade pelo 
preparo e pela qualidade inclusive as constantes na NBR 7212 (ABNT, 2012) é da concreteira. Os documentos relativos a análises, ensaios, dosagens e resultados devem ser arquivados pela usina e na obra por seu responsável técnico. Estes documentos poderão ser alvo de análise a fim de identificar inconstâncias com outras etapas do processo de planejamento do início da etapa de concretagem.

A NBR 12655 (ABNT, 2006) fundamenta a importância deste estudo, inclusive indicando a responsabilidade civil:

a) atendimento a todos os requisitos de projeto, inclusive quanto à escolha dos materiais a serem empregados;

b) aceitação do concreto.

Para aceitação a referida norma expõe quatro tipos de definições de responsabilidades: aceitação do concreto por exame sistemático; aceitação do concreto fresco efetuada durante a descarga da betoneira; aceitação definitiva do concreto e recebimento do concreto com a aprovação da documentação correspondente e relativa às etapas de preparo do concreto e sua aceitação.

Não somente a qualidade de cada insumo utilizado no concreto influencia seu desempenho, como outros aspectos relacionados à gestão, como a estocagem, medidas, misturas, entre outros.

Entretanto os procedimentos de aceitação não são feitos à revelia. A NBR 12655 (ABNT, 2006) estabelece os seguintes ensaios para controle de qualidade: ensaio de consistência, ensaios de resistência à compressão e de módulo de elasticidade. E estabelece que o concreto deve ser recebido unicamente desde que atendidas todas as condições estabelecidas na referida norma.

Corroborando com o exposto, a NBR 15575 (ABNT, 2013) estabelece requisitos mínimos de desempenho que devem ser atendidos durante a vida útil de projeto, sob as diversas condições de exposição (ação do peso próprio, sobrecargas de utilização, atuações do vento e outros), os quais estão relacionados a sua estabilidade, provisão de segurança aos usuários, o não prejuízo de partes móveis da edificação como portas, janelas e instalações, não repercussão em estados inaceitáveis de fissuração de vedação e acabamentos, entre outros.

As manifestações patológicas que acometem os edifícios podem ocorrer por diversos fatores diferentes. Este fenômeno pode ter origem desde o projeto da edificação, execução da obra, materiais utilizados, uso inadequado do edifício até a falta de manutenção. Segundo Garcia e Liborio (1998), as manifestações patológicas em estruturas, geralmente não tem uma só causa, mas sim uma participação de vários fatores, sendo comum encontrar estruturas de edifício que possuem um erro construtivo ou de concepção e que não acarreta danos importantes, por outro lado é possível uma estrutura estar fortemente comprometida devido ao acúmulo de diversos pequenos erros.

Uma das causas citadas por Silva (2012), que estudou manifestações patológicas em vedações de edificações residenciais a partir da análise de dados de assistências técnicas, compreendem falhas que ocorrem pela falta de controle dos serviços, omissão de algumas especificações que constem em projeto e falta de cumprimento das normas técnicas.

Problemas como corrosão de armadura, carbonatação, deformabilidade excessiva da estrutura, excesso de permeabilidade e lixiviação são alguns problemas que podem surgir nas estruturas e que, segundo Bastos (2011), quase sempre significam transtornos e 
aborrecimentos aos proprietários e/ou usuários da edificação, gerando elevados custos de reparo para os construtores.

Entre os citados, a deformabilidade excessiva dos elementos estruturais é um dos fatores preponderantes das manifestações patológicas nas vedações. Segundo Silva (2012), a deformabilidade está ligada a várias características, entre elas as propriedades mecânicas do concreto que tem como principais fatores o módulo de elasticidade secante e a resistência à tração.

Para se evitar alguns tipos de erros na execução de estruturas de concreto armado, de acordo com Garcia e Liborio (1998), todos os participantes dessa fase, do operador de vibrador ao engenheiro responsável, devem saber exatamente como executar seus serviços. A falha de uma dessas pessoas por qualquer motivo pode causar graves erros e grandes prejuízos.

\section{MÉTODO DE PESQUISA}

A pesquisa, de acordo com o método científico, consiste em um estudo de múltiplos casos.

\subsection{Escolha dos casos}

Quanto aos critérios para escolha dos casos, foram consideradas construtoras que atuam na cidade de Goiânia e que possuem sistema de gestão certificado pelo PBQP-h e/ou ISO 9001 pois pressupõe-se que possuam maior controle de qualidade em seus processos. Também foram consideradas obras em fase de execução dos serviços de concretagem, sendo eles na infraestrutura ou na estrutura, preferencialmente para edificações multipavimentos. Tornou-se imprescindível a disponibilização e aceitação para a pesquisa por parte das empresas selecionadas, devido ao nível de investigação que necessitava, além do acompanhamento por observação direta dos processos relacionados à concretagem, a análise documental e a aplicação de checklist. Os dados foram coletados no segundo semestre do ano 2013.

\subsection{Instrumentos de coleta e análise dos dados}

Um checklist para coleta dos dados foi composto por itens considerados importantes retirados de bibliografias, referências normativas da International Organization for Standardization (ISO) e Associação Brasileira de Normas Técnicas (ABNT), além de entrevistas feitas com especialistas da área de concreto, bem como técnicos de laboratórios de ensaios para concretos.

O checklist foi construído em 4 grupos de questões, sendo estes referentes:

- ao projeto: por exemplo, se o projeto contempla itens como fcj de desforma, especificação do módulo de elasticidade, limites de fissuração, requisitos de durabilidade da estrutura durante sua vida útil, entre outros;

- à responsabilidade da concreteira: por exemplo, cumprimento do prazo requisitado, entrega de nota fiscal, entrega coerente com o pedido, entre outros;

- à obrigação do responsável pela obra: por exemplo, responsabilidade pelo recebimento do concreto, conferência do Slump Test, conferência dos requisitos solicitados à concreteira de acordo com o projeto, entre outros;

- aos ensaios e ações de controle: por exemplo, retirada de corpos de prova para ensaio do módulo de elasticidade, comprovação da rastreabilidade do concreto, entre outros. 
A análise documental consistiu na avaliação de projetos, cronogramas de obra, registros a respeito do recebimento do concreto, notas fiscais do concreto entregue e resultados laboratoriais. Foram realizados no decorrer das visitas in loco registros fotográficos de fatos relevantes à discussão do que foi sugerido como mínimo aceitável para garantir a qualidade do concreto usinado.

\section{RESULTADOS E DISCUSSÃO}

\subsection{Síntese dos dados coletados}

O Quadro 1 reúne as informações a respeito dos quatro casos estudados.

\section{Quadro 1 - Caracterização dos casos estudados}

\begin{tabular}{|c|c|c|c|}
\hline $\begin{array}{c}\text { CASO A } \\
\text { Entrega } \\
\text { em } \\
11 / 2015\end{array}$ &  & $\begin{array}{l}\text { Residencial e } \\
\text { comercial } \\
2 \text { torres } \\
28 \text { e } 37 \text { pavimentos } \\
\text { Alto padrão }\end{array}$ & $\begin{array}{l}\text { Estrutura em concreto armado/ } \\
\text { alvenaria com bloco cerâmico/ } \\
\text { laje nervurada }\end{array}$ \\
\hline $\begin{array}{c}\text { CASO B } \\
\text { Entrega } \\
\text { em } \\
02 / 2015\end{array}$ & & $\begin{array}{l}\text { Residencial } \\
3 \text { torres } \\
14 \text { pavimentos } \\
\text { Médio padrão }\end{array}$ & $\begin{array}{l}\text { Alvenaria estrutural de blocos } \\
\text { de concreto/ laje de concreto } \\
\text { armado }\end{array}$ \\
\hline $\begin{array}{c}\text { CASO C } \\
\text { Entrega } \\
\text { em } \\
04 / 2015\end{array}$ &  & $\begin{array}{l}\text { Residencial } \\
1 \text { torre } \\
38 \text { pavimentos } \\
\text { Alto padrão }\end{array}$ & Fundação tipo tubulão \\
\hline $\begin{array}{c}\text { CASO D } \\
\text { Entrega } \\
\text { em } \\
05 / 2015\end{array}$ & & $\begin{array}{l}\text { Residencial } \\
1 \text { torre } \\
34 \text { pavimentos } \\
\text { Alto padrão }\end{array}$ & $\begin{array}{l}\text { Estrutura em concreto armado/ } \\
\text { alvenaria com bloco cerâmico }\end{array}$ \\
\hline
\end{tabular}

Fonte: autores

O Quadro 2 sintetiza e ilustra parte dos principais dados obtidos nos casos A e B. 


\section{Quadro 2 - Síntese dos dados obtidos nos casos estudados}

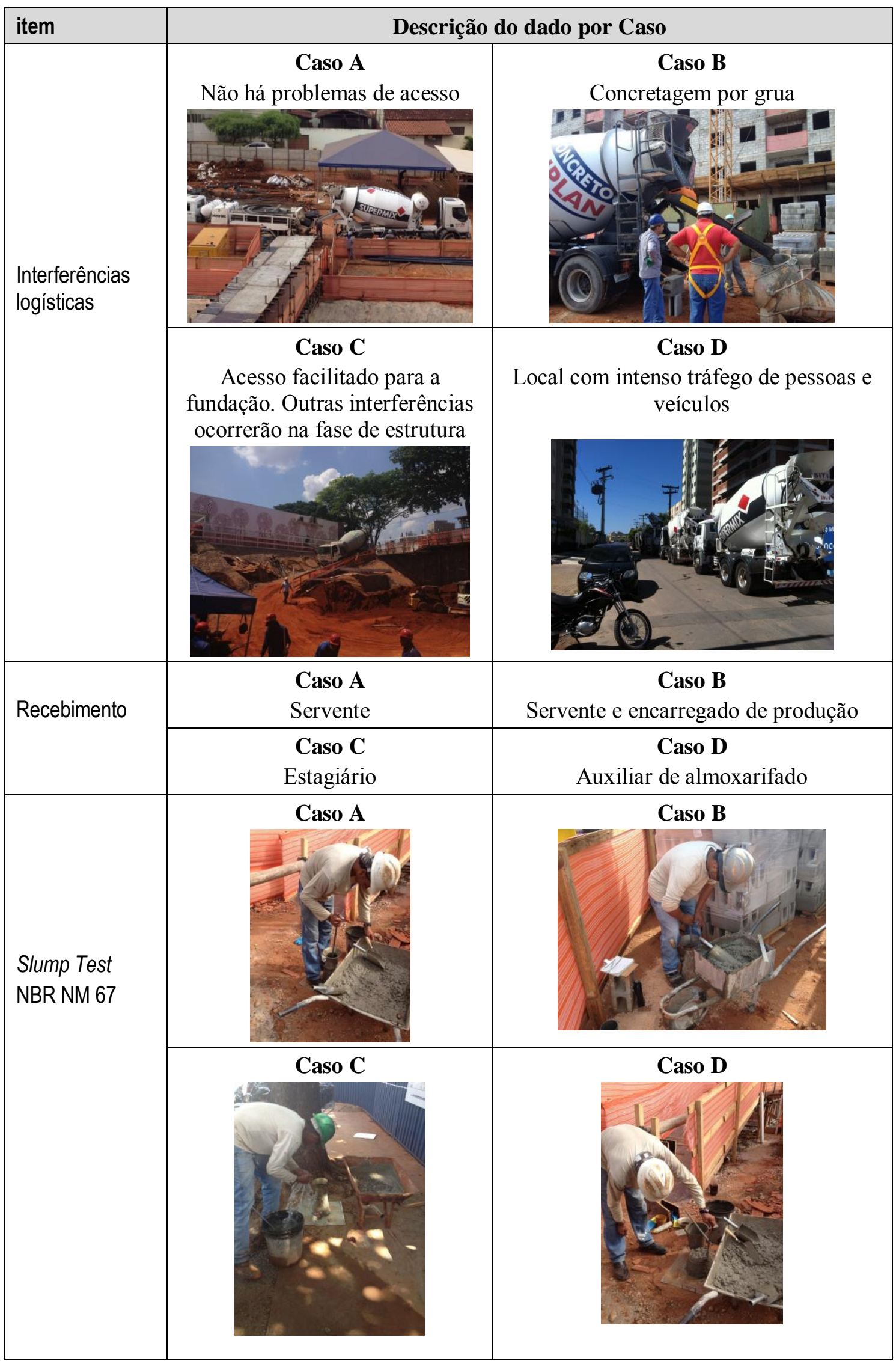


Quadro 2 - Síntese dos dados obtidos nos casos estudados (continuação)

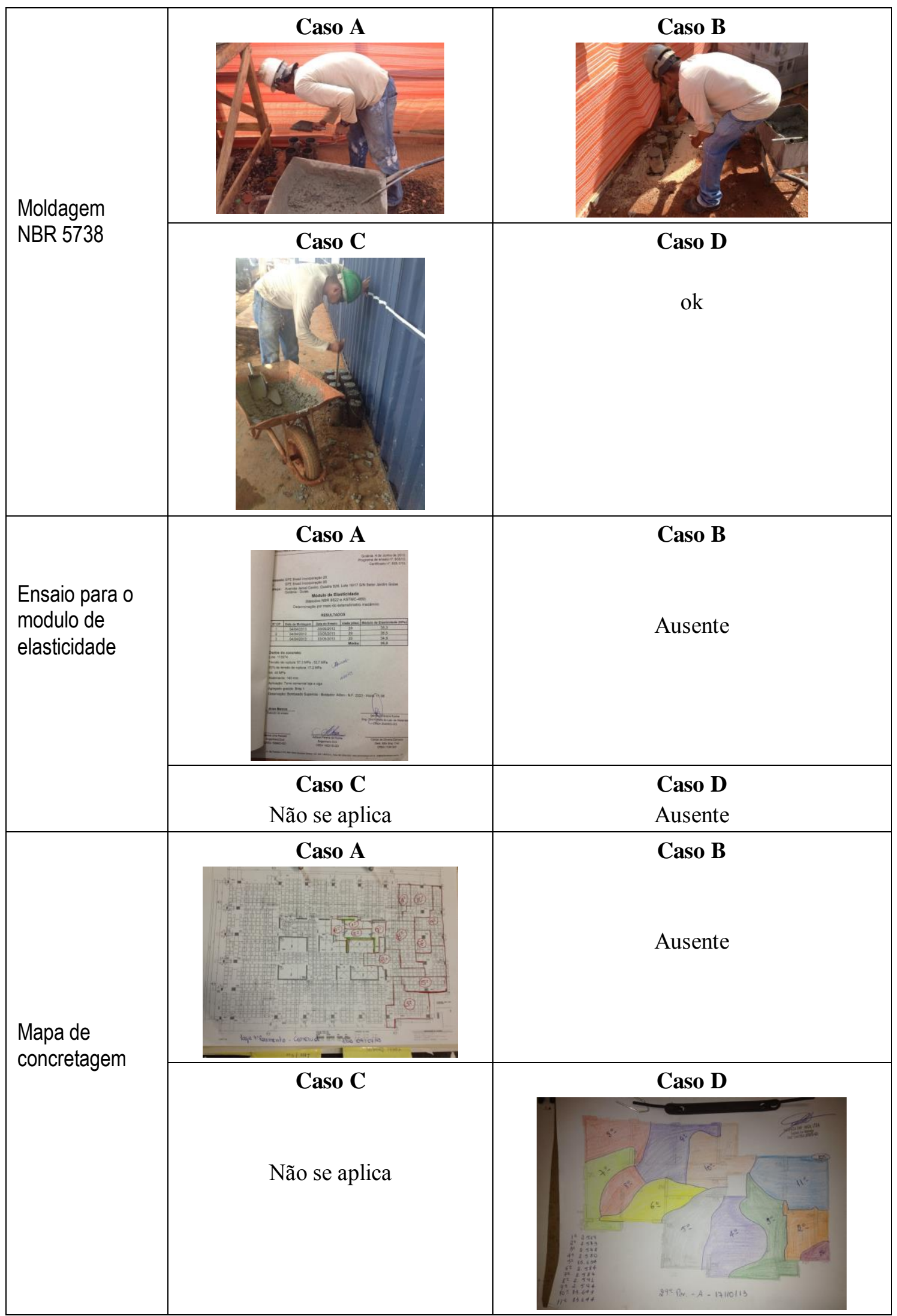

Fonte: autores 


\subsection{Resultados do checklist para verificação do controle no recebimento}

Ao se aplicar o checklist constatou-se que todos os caminhões em todos os casos foram aceitos. Foram relatados que nos empreendimentos A e D já houve rejeição de caminhões, no caso A devido à diferença do abatimento no Slump Test em relação ao solicitado e no caso D porque o caminhão chegou equivocadamente na obra.

A Figura 1 ilustra o gráfico que reúne os resultados obtidos na aplicação do checklist.

Figura 1 - Itens de conformidade relativos ao controle no recebimento do concreto para todos os casos

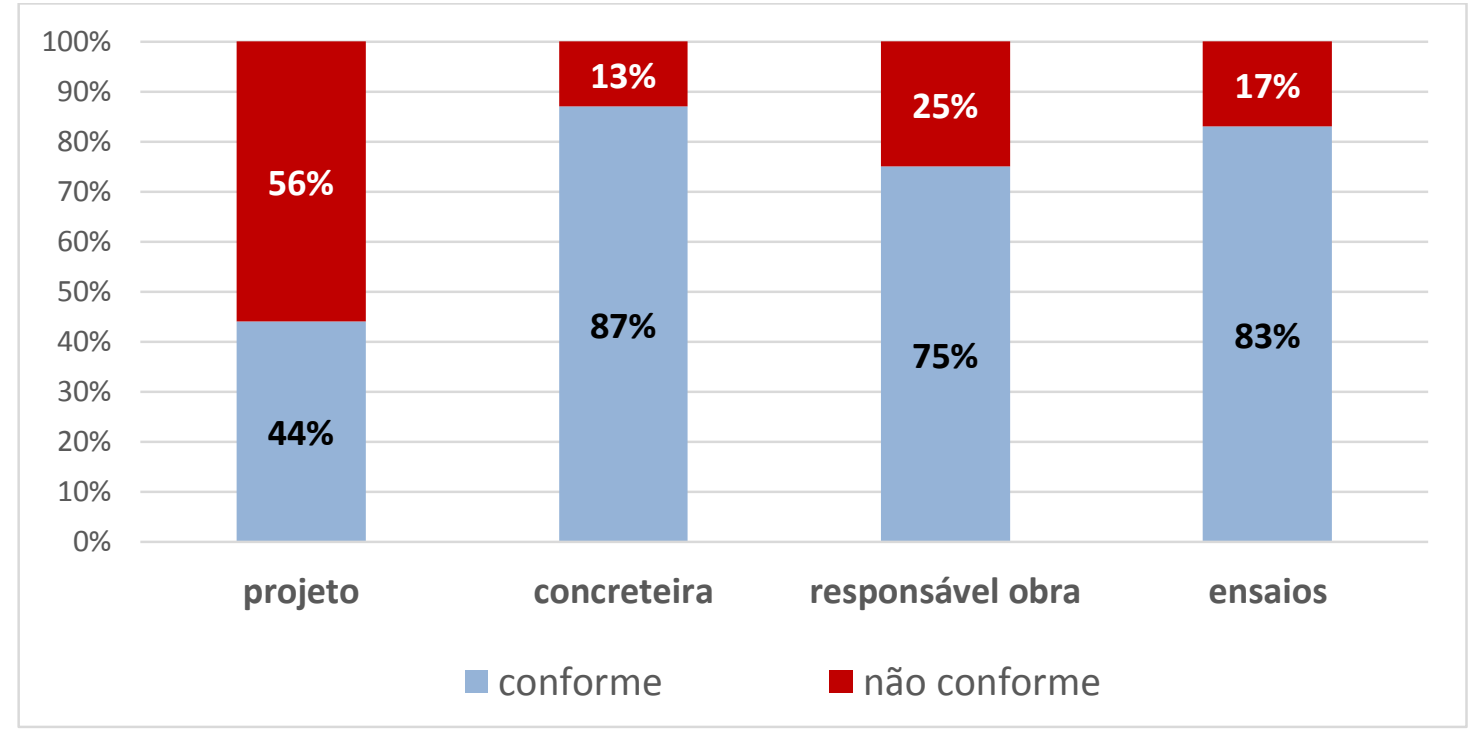

Fonte: autores

Após a compilação dos resultados, segue a análise discriminada.

\subsection{Quanto ao projeto e responsabilidade do projetista}

Em nenhum dos projetos constavam a resistência característica à compressão na idade de desforma (fcj), o módulo de elasticidade mínimo na idade de desforma, a classe de agressividade ambiental (CAA) considerada nos cálculos e requisitos de durabilidade da estrutura durante a vida útil.

Ainda que a relação água cimento possa não reduzir a resistência do concreto ao utilizar aditivos, há a possibilidade de aumento excessivo da porosidade sendo porta de entrada para agentes agressivos como substâncias a base de sulfatos, cloretos, carbonatos e umidade, que em contato com a armadura geram despassivação e posterior corrosão. $\mathrm{O}$ módulo de elasticidade da estrutura tem ligação direta com manifestações patológicas das alvenarias e revestimentos devido sua influência nas deformações estruturais podendo gerar fissuras, contrariando orientações da norma NBR 15575 (ABNT, 2013).

Dos casos analisados apenas no empreendimento $\mathrm{C}$ o projeto apresentava a faixa de valores de abatimento do tronco de cone, dimensões máximas características dos agregados e limites de fissuração. Porém somente nos projetos do caso $\mathrm{C}$ não constavam a relação entre água e cimento e o módulo de elasticidade considerado. 


\subsection{Quanto às responsabilidades da empresa concreteira}

Em dois casos, A e D, os caminhões chegaram com um atraso superior a 30 minutos e no caso B houve atrasos em serviços preliminares atrasando o lançamento do concreto. Por serem alvos de fiscalização frequente, verificou-se que em todos os casos as notas fiscais estavam de acordo com o solicitado.

\subsection{Quanto às obrigações do responsável pela obra}

Uma situação recorrente nas obras estudadas foi a delegação da função de recebimento do concreto. Este foi realizado por pessoa diversa à definida em norma para esta função (proprietário e o responsável técnico da obra). São eles normalmente auxiliares de almoxarifado, serventes e estagiários, pessoas que não possuem qualificação pra tal atividade. Entretanto houve a conferência das notas fiscais no ato da entrega do concreto.

Em contraponto ao item 4.3 da NBR 12655 (ABNT, 2006) somente no caso D o engenheiro não solicitou o concreto definindo a dimensão máxima do agregado, ficando esta escolha a cargo da concreteira.

\subsection{Quanto aos ensaios e ações de controle}

Apenas no empreendimento A foram retiradas amostras para ensaios de verificação do módulo de elasticidade. Por este ensaio não ser citado nos métodos de verificação da NBR 12655 (ABNT, 2006), ele é pouco realizado pelas empresas construtoras. A falta desta informação pode acarretar decisões equivocadas do engenheiro responsável pela execução da obra, quanto a retirada do cimbramento e principalmente gerar deformações excessivas na estrutura. Apenas no caso A foram moldados corpos de prova para este ensaio.

E apenas no empreendimento B não existiu nenhum mecanismo de rastreabilidade de concretagem.

\section{CONSIDERAÇÕES FINAIS E INDICADORES DE QUALIDADE}

Pôde-se constatar que grande parte dos problemas encontrados na etapa de recebimento do concreto está concentrada em questões de projeto. Várias informações ausentes nos projetos poderiam ser consideradas a partir da retroalimentação dos projetistas. Entretanto, foi constatado que tais informações também são desconhecidas ou pouco consideradas pelos responsáveis técnicos das obras. Um exemplo disto está na importância em controlar o módulo de elasticidade que pode trazer à edificação acabada transtornos e manifestações patológicas relacionadas às alvenarias e revestimentos.

É possível inferir indicadores de qualidade para etapa de recebimento de modo a nortear os envolvidos no processo (projetistas, executores de obras e concreteiras) e facilitar a retroalimentação do sistema de gestão da qualidade. São sugeridos:

- Quantidade de itens de requisitos mínimos ausentes na etapa de projeto do checklist por quantidade de itens totais na mesma etapa;

- Número de caminhões que chegaram atrasados pela quantidade de caminhões enviados por dia;

- Número de caminhões que chegaram equivocadamente em seus destinos pelo número de caminhões enviados por mês;

- Quantidade de caminhões rejeitados por caminhões requisitados; 
- Quantidade de ensaios que não atendem o especificado pela quantidade de ensaios realizados (para cada tipo de ensaio);

- Número de itens de requisitos mínimos do checklist não controlados no recebimento do concreto pelo número total de itens totais a cada recebimento.

O emprego de indicadores de qualidade para o recebimento como os propostos podem auxiliar, por meio da retroalimentação de dados, no controle e consequentemente na eficiência da gestão.

Vale ressaltar que as empresas escolhidas para a pesquisa possuem grande experiência no ramo da construção sendo certificadas pelo Programa Brasileiro da Qualidade e Produtividade do Habitat e International Organization for Standardization (ISO). Entretanto ficou evidenciada a grande quantidade de não conformidades nos procedimentos adotados pelas empresas em relação ao checklist proposto, o que permite inferir sobre a necessidade de uma maior conscientização em relação ao controle da qualidade por parte dos envolvidos nesta relevante etapa da cadeia produtiva.

\section{REFERÊNCIAS}

ABNT - ASSOCIAÇÃO BRASILEIRA DE NORMAS TÉCNICAS. NBR 15575: Edifícios habitacionais de até cinco pavimentos - Desempenho. Parte 1: Requisitos gerais. Rio de Janeiro, 2013.

NBR 9050: Acessibilidade a edificações, mobiliário, espaços e equipamentos urbanos. Rio de Janeiro, 2005, 97p.

NBR 5738: Concreto - Procedimento para moldagem e cura de corpos-de-prova. Rio de Janeiro, 2003. 6 p. $\overline{2012.21 \mathrm{p} .}$

NBR 7212: Execução de concreto dosado em central - Procedimento. Rio de Janeiro,

NBR 12655: Preparo, controle e recebimento de concreto. Rio de Janeiro, 2006.22 p.

NBR NM 67: Concreto - Determinação da consistência pelo abatimento do tronco de cone. Rio de Janeiro, 1998. 8 p.

BASTOS, P. K. X. Construção de Edifícios. Rio de Janeiro. UFJF, 2011.

CUPERTINO, D. Análise de solicitações de assistência técnica em empreendimentos residenciais como ferramentas de gestão. 2013. 167 f. Dissertação (Mestrado em Engenharia Civil) - Universidade Federal de Goiás, 2013.

GARCIA, C. C.; LIBORIO, J. B. L. A incidência de patologias geradas pela falta de controle e de qualidade e dos canteiros de obras. São Paulo: USP, 1998.

OBATA, S. H.; SOUZA, U. E. L. Características geométricas relevantes para controle da qualidade dos produtos moldados de concreto armado. São Paulo: EPUSP, 2001.

SILVA, B. C. Investigação de manifestações patológicas em alvenaria de edifícios multipavimentos por meio de registros de assistência técnica. 2012. 196 f. Dissertação (Mestrado em Engenharia Civil) - Universidade Federal de Goiás, 2012. 